This item was submitted to Loughborough's Research Repository by the author.

Items in Figshare are protected by copyright, with all rights reserved, unless otherwise indicated.

\title{
An approach to context in human-computer communication
}

PLEASE CITE THE PUBLISHED VERSION

http://dx.doi.org/10.1515/SEM.2008.024

\section{PUBLISHER}

(C) Walter de Gruyter

VERSION

VoR (Version of Record)

LICENCE

CC BY-NC-ND 4.0

REPOSITORY RECORD

Connolly, J.H., Alan Chamberlain, and lain W. Phillips. 2019. "An Approach to Context in Human-computer Communication". figshare. https://hdl.handle.net/2134/9206. 
This item was submitted to Loughborough's Institutional Repository (https://dspace.lboro.ac.uk/) by the author and is made available under the following Creative Commons Licence conditions.

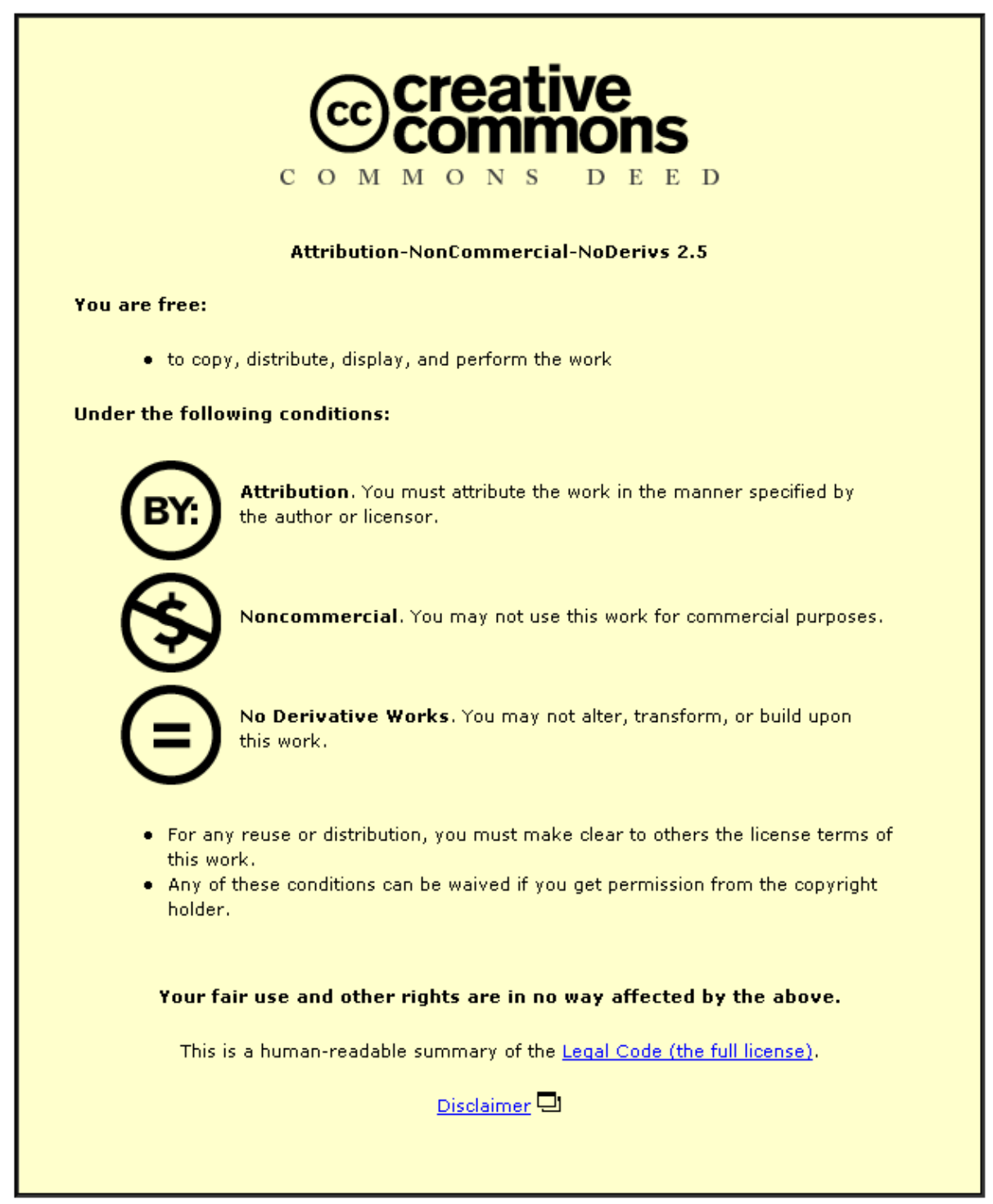

For the full text of this licence, please go to: http://creativecommons.org/licenses/by-nc-nd/2.5/ 


\title{
An approach to context in human-computer communication
}

\author{
JOHN H. CONNOLLY, ALAN CHAMBERLAIN, \\ and IAIN W. PHILLIPS
}

Abstract

A comprehensive framework is presented for the analysis or description of context in relation to human-computer communication, in a manner that is also consistent with the contextual analysis of interpersonal communication among humans. Following a discussion of the nature of context, a hierarchically structured framework is proposed, which distinguishes between those contextual factors that are intrinsic to the communication process and those extrinsic factors that are classed as situational. Both of these overall classes are subdivided into broader and narrower categories, and the situational context is additionally analyzed in terms of physical and socio-cultural factors. Cognitive aspects of context are also included within the treatment, while allowing for the differences that exist between human and computerbased representations. Finally, the application of the framework to various aspects of human-computer communication is discussed, with a view to the resolution of attendant problems.

Keywords: context; context-aware; computing; discourse; dialogue; human-computer interaction.

\section{Introduction}

In a recent paper, the present authors propose an approach to humancomputer communication, founded upon a concept of 'discourse' which is intended to be equally applicable both to human-computer interaction (HCI) and to interpersonal, human-human interaction (HHI); see Connolly, Chamberlain and Phillips (2006). However, as is well known, every discourse takes place within a context; and consequently, no discoursebased account of human-computer communication can be considered complete without a contextual component. Given that our previous paper 
does not offer a systematic treatment of context, it is our purpose here to attempt to remedy that deficiency.

As before, in the interests of consistency, we would wish to foster an approach that is applicable not only to HCI but also to HHI. The fact that the subject of context has been addressed by many authors both in the field of computing and in the domain of linguistics provides an encouraging starting-point here.

As would be expected, there has been particular interest in the topic of context on the part of those engaged in research in the area of computing concerned with 'context-aware' (CA) systems. The latter are computer-based systems, usually networked, that are equipped to sense what is going on in their environment, for example the approach of a human being, the ambient temperature, and so forth. Clearly, communication involving such systems must be accommodated within our approach.

What we propose, then, is to offer a framework for the analysis and description of context that is applicable to HCI and also consistent with the contextual treatment of HHI. In developing a contextual framework of this kind, we shall need to overcome the following obstacles:

(1) a. No existing contextual framework in the field of either linguistics or computing is fully adequate. We cannot, therefore, for example, take an established framework from linguistics and apply it directly to HCI.

b. Contextual frameworks proposed in linguistics are not generally directed at multimodal communication, whereas this has become the normal method of interaction in HCI; and they are certainly not designed for the analysis of communication with CA systems.

c. Contextual frameworks designed with CA systems in mind tend to focus on the context of the system itself, whereas linguistically oriented frameworks focus on the discourse between the participants (or interlocutors) in the communicative activity. This presents a clear source of potential inconsistency.

d. Linguistically oriented approaches often include mental activity as a contextual factor, whereas in the case of HCI, the system obviously does not possess a human mind.

Nevertheless, we believe that these problems are not insuperable, and hence, we shall attempt to develop a contextual framework that fulfils the requirements outlined above. It will be built around the concept of discourse proposed in our previous paper. 


\section{On the nature of context}

We need to begin by offering some general remarks about context. First of all, context is a relative term, which presupposes some focus of interest, such as a user-system dialogue (USD). A USD is a situated, interactive discourse between a user and a computer-based system; and it is the USD, in whole or part, that we shall regard, for present purposes, as the focal event within HCI. The context of that particular event lies in what surrounds it, and so the context is relative to the particular focus of interest; cf. Goodwin and Duranti (1992: 3).

However, if we are to arrive at a workable concept of context, we cannot equate it with all and everything that surrounds the focal event. That would be immense and impossible to analyze or describe; cf. Cook (1990: 6). Rather, we need to restrict context to what is relevant to our analysis of the relationship between the situated dialogue (or dialogue-excerpt) and its surroundings. This, in turn, depends on our purpose in carrying out a contextual analysis. For example, consider the following excerpt from a USD between a user (U) and a system (S):

(2) a. U: Selects from a тепи the item

Empty Trash

b. S: Displays the text

Are you sure that you want to delete these files permanently?

c. $\quad$ Displays buttons labelled

Yes No

d. U: Clicks on the button labelled Yes

e. S: Deletes the files from the Trash folder

Relevant phenomena here include the intentions of the user and the identities of the computer files to be deleted, whereas considerations such as the time of day may be presumed irrelevant and hence not regarded as part of the actual context (even though the time is undoubtedly part of the overall circumstances surrounding the focal event). On the other hand, if the user had been setting an alarm (in the form of an audible bleep) to go off two hours later, then temporal factors would have been highly relevant and would therefore have been treated as contextual under those conditions.

It is thus clear that context is not a purely objective phenomenon that subsists independently in the world; cf. Cook (1990: 6). Rather, it is a construct, in that it constitutes a product of analysis. Nothing is inherently contextual. Rather, contextuality (the status of belonging to the context) 
is an emergent property of the relevant phenomena; cf. Dourish (2004: 20-23).

Context and discourse are strongly interrelated, and there is a constant interplay between the two. For example, at the outset of (2), before the user carries out the communicative act (2a), the following constitute facts about the context:

(3) a. The user intends the contents of the Trash folder to be deleted.

b. The contents of the Trash folder are not (yet) earmarked for deletion.

Fact (3a) is what stimulates the user to issue the command (2a). In this way, the context influences the discourse. However, the issuing of (2a) alters the context by changing the truth-value of (3b) from true to false. So now it is the discourse that has had an impact upon the context. As is apparent, this interplay between dialogue and context continues throughout the excerpt.

The fact that changes in context take place as a discourse proceeds shows that context does not provide a merely static backcloth to the focal event, but is dynamic: cf. Goodwin and Duranti (1992: 5). Of course, this does not mean that all aspects of context have to change during the discourse; for example, the participants may well be constant throughout; cf. House (2006: 342-343). Nevertheless, at least some aspects of context do evolve continually as the discourse proceeds. Bunt (2000: 26) terms these the 'local' aspects of context, as opposed to the 'global' aspects that remain constant throughout the discourse.

We may sum up our view of context as follows:

(4) Context is an analytical construct applying to those phenomena that:

a. surround a given focal event,

b. are relevant to that focal event, and

c. are liable to enter into dynamic interplay with that focal event.

We may now proceed to present our framework for the analysis and description of context.

\section{Discoursal context}

The term 'context' originates in the study of human language, and so it is not surprising that linguistics supplies a number of useful principles here. Among these we may note the distinction that is frequently drawn between the following: 
(5) a. Linguistic context, which may be subdivided into:

i. Co-text: the narrower linguistic context

ii. Inter-text: the broader linguistic context

b. Situational context

(Terminology varies, but this need not concern us here.) 'Linguistic' context comprises that part of the context that consists of language, whereas 'situational' context constitutes the remainder of the context and is therefore non-linguistic in character. By way of example, suppose that the following HHI takes place in the form of an email exchange between two interlocutors called Cath (C) and Dave (D):

(6) a. C: What time is the staff meeting?

b. D: It's been postponed to three o'clock.

c. By the way, a couple of weeks ago, Elaine sent me a message saying that applications are down 10 percent this year, and so I expect this subject will come up at the meeting.

Here, the situational context includes the staff meeting, the time, and the applications received. As for the linguistic context, let us first of all focus on the word 'it' in (6b). In order to interpret this pronoun, it is necessary to cross-refer to its antecedent, the noun phrase 'the staff meeting' in (6a). Hence, this noun phrase supplies the essential context for the pronoun; and being a unit of language, it belongs to the linguistic rather than the situational context. Moreover, because it occurs in the same discourse as the focal excerpt ('it'), the noun phrase in question is said to be part of the 'co-text'; cf. Halliday (1999: 3). Compare this with the earlier message (from Elaine) referred to (6c), which is also part of the linguistic context of the HHI, but which comprises another discourse. Because it does not belong to the same discourse (6), it cannot be regarded as co-text, but instead it is classified as 'inter-text'; cf. Cook (1990: 3).

However, although the distinction between linguistic and situational context offers a useful starting-point, it is not adequate for our purposes here. The reason for this is that discourse, be it HHI or HCI, is often multi-modal in character; cf. Kress and van Leeuwen (1996: 342-343). In HHI, spoken language is normally accompanied by non-verbal communication such as gestures, while written documents often contain illustrations such as pictures or graphs. Again, in HCI, multi-modal interaction is the norm in activities such as using the world-wide web, where pictorial elements (icons) are commonplace. If we focus on a particular discourse, or excerpt, and attempt to analyze its context in terms of the distinction between 'linguistic' and 'situational context,' then the nonverbal constituents of the discourse, being non-linguistic, have to be 
assigned to the situational context, along with factors that are external to the discourse, such as the time or location (where these are relevant).

This, in our view, is to draw the line in the wrong place. The most salient distinction is, clearly, between those contextual phenomena that reside within the communication process itself and those that are exterior to it; and this is, indeed, the original motivation behind the linguistic/ situational division. We therefore propose a distinction between the following:

(7) a. Discoursal context, which may be subdivided into:

i. Narrower discoursal context

ii. Broader discoursal context

b. Situational context

The 'situational' context denotes those aspects of the context that do not form part of any discourse, whereas the 'discoursal' context encompasses all contextual phenomena that belong to any discourse, whether unimodal or multimodal. If the focal event constitutes an excerpt from a particular discourse, then any contextual elements belonging to the same discourse are part of the 'narrower' discoursal context, while any contextual material belonging to a discourse that neither constitutes nor contains the focal event is part of the 'broader' discoursal context.

Let us apply these distinctions to a simple example of a USD between a user (U) and a system (S):

(8) a. U: Double-clicks on an icon labelled AutosReport.doc, which designates a file containing a half-complete document about automobiles

b. S: Opens the document in a word-processing application

c. U: Chooses from a menu the option Insert, and from a submenu the option Picture

d. S: Displays a dialogue box containing an icon labelled Alloys, which designates a file containing an image of a set of alloy wheels, previously downloaded from a web-site called www.WheelingWithFeeling.com [ fictitious at the time of writing]

e. U: Clicks on the icon

f. S: Displays buttons labelled

Insert Cancel

g. U: Clicks on the button labelled

Insert

h. S: Inserts the image into the document

i. $\mathrm{U}:$ Types beneath the image the text 
This is a set of trendy wheels, courtesy of www .WheelingWithFeeling.com

If we focus on the piece of text in (8i), then we may treat the image of the wheels as belonging to its narrower discoursal context, given that it is part of the same document, and it is relevant in that it clarifies the interpretation of the word 'this' in the text. The web-site from which it was downloaded is also a (complex) document, but is not part of the focal discourse and therefore belongs to the broader rather than the narrower discoursal context. The situational context includes the intentions of the user in producing the document, the software available on the system and the connection to the Internet that made the download possible.

\section{Situational context}

\subsection{Hierarchical structure}

Let us now turn our attention to the situational context. Just as the discoursal context can be divided into broader and narrower aspects, so too can the situational context. Thus, in parallel with (7a), and following the practice of authors such as Cicourel (1992: 293-296), we draw a distinction between the following:

(9) a. Narrower situational context

b. Broader situational context

The 'narrower' situational context is supplied by the immediate surroundings of the discourse. For example, if an individual is engaged in a USD with a computer in a laboratory, then the interior of the laboratory may be deemed to supply the immediate context. In HHI, the immediate context would, in a typical case, be limited to the range within which the participants can see and hear each other. On the other hand, any situational contextual phenomena lying beyond the horizon of the immediate context belong to the 'broader' situational context. An example could be the laws governing what may and may not be downloaded from the web with in the country where a USD is taking place (assuming, of course, that this matter is relevant to the interaction).

The combination of (7) with (9) implies a hierarchical view of context, as shown in figure 1. The fact that it is hierarchically structured in this way constitutes another salient property of context.

However, there is an additional dimension to the structure of the situational context. Stamper (2001: 116-118), in his influential work on 


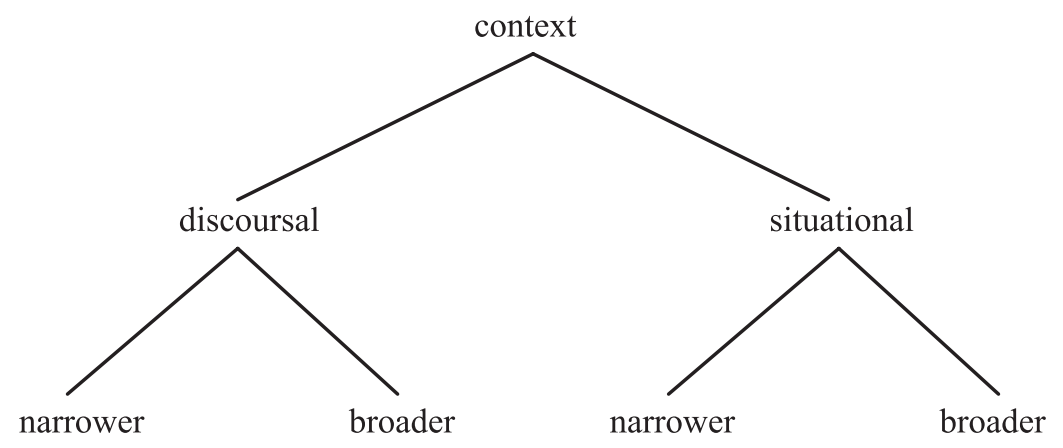

Figure 1. The basic hierarchical structure of context

semiotics, maintains a strong distinction between the social world and the physical world. In accordance with this principle, we may draw a distinction between the following:

(10) a. Socio-cultural context

b. Physical context

This distinction between physical phenomena, on the one hand, and social and cultural phenomena, on the other, applies both to the narrower and to the broader aspects of the situational context, as will be demonstrated in what follows.

\subsection{Narrower situational context}

Following Hymes (1972: 60), we may distinguish between the following:
a. Setting
b. Scene

The 'setting' is the immediate physical context, whereas the 'scene' comprises the immediate socio-cultural context. Imagine, for example, that on a particular day a university computer laboratory (a physical setting) is the scene of a practical programming class for university students during the afternoon, but in the evening it is the scene of a robbery in which a number of the computers are stolen. The two activities in question differ considerably in terms of how they are viewed within society and are therefore justifiably described as different scenes happening in the same setting.

The setting may be described in terms of the following (insofar as they are relevant): 
(12) a. Time

b. Place

c. Physical entities present (be they animate or inanimate) and their physical attributes and actions

d. Environmental considerations, such as temperature

See further Abowd and Mynatt (2000: 37) and Amor (2002: 30). Moreover, when computers are involved in the communication process, they provide some additional contextual factors that do not apply to traditional HHI. These factors include the following (which again pertain to the physical surroundings of the interaction):

(13) a. The computer hardware involved

b. The software running on the system

c. Network connectivity and bandwidth

See further Burkhardt et al. (2002: 207-208). For example, a user seeking to download a piece of music from the web and play it in real-time on his or her computer may be thwarted if the computer does not contain a suitable soundcard, or if the music-player application installed on the computer is incompatible with the version of the operating system by which the computer is controlled, or if the network is excessively slow.

As for describing the scene, considerations such as the following may be included (again, insofar as they are relevant):

(14) a. The participants in the discourse and their social attributes, for example the roles they play (such as author or addressee), their attitudes and their level of computer literacy

b. The occasion

c. The intended and actual outcomes of the discourse

See further Hymes (1972: 60-61). The participants in the discourse are, most centrally, those who are intended to be involved in it. These are described by Goffman (1981: 131-137) as the 'ratified' participants. However, there may be other relevant individuals who may be able to overhear or eavesdrop. These are the 'unratified' participants; cf. also Pemberton (1996). Participants, ratified or otherwise, are treated as part of the socio-cultural context because they are involved in the inherently social activity of communication and are identified in relation to their intrinsically social roles in respect of this process. (Of course, they are also part of the physical setting, as animate entities.)

It is not only the identity of participants and other entities that may be contextually relevant, but also their attributes and their actions. For example, if during the course of an interaction between a user and a system, 
the system presents the user with error messages containing technical terminology, then the intelligibility of the messages, and hence the success of the communication, is going to depend crucially upon whether or not the user is familiar with the terminology and with the workings of computerbased systems. As for the possibility of contextually significant actions (in addition to those involved in the communication activity itself), an example would be where a mobile-computer user, interacting with a fixed system via a network, moved out of the range of the network-coverage and consequently lost the communication link.

Two complications arise at this point. First, it is quite possible that the participants may not be co-located in time and space. Suppose, for example, that Dave is in Cardiff today and sends an email to Elaine, who reads it in Swansea tomorrow. In that case, the context of their computermediated communication is spatio-temporally 'distributed,' and the immediate context of Dave, when he sends the message, and that of Elaine, when she reads the message, would need to be described separately. Second, as everyone knows, authors may refer to situations that are not in the immediate context of either themselves or any other of the discourse participants. For example, Dave's email could have been about events in Paris. In that case, the remote situation described in the message would constitute what Martinec (2000: 244) calls a 'displaced' context.

The occasion (14b) describes the social circumstance, such as an informal conversation, a formal conference, a quest for information, a dispute, and so on. Any of these may be either spoken or written, and may or may not involve interaction with computers.

As for the intended outcomes of the discourse (14c), these reside in the purposes of the interlocutors. Following Bunt (2000: 28), it is useful to distinguish between the communicative purpose of a message (for example, to ask a question and to have it successfully understood by the addressee) and the ulterior purpose lying behind the message (for example, to find out how much a particular train fare is). If all goes well, the actual outcome will match the intended outcome. However, it is always possible that this will not be so, for example if the message is misunderstood.

In relation to HCI, considerations of purpose tend to be described in relation to the task in which the user or users are engaged. An example would be the quest for information about share prices by means of the web. 'Task,' which is an identifiable goal-directed activity situated within the social world, is a particularly important consideration in HCI, inasmuch as systems are expected to be designed in such a way as to facilitate task-accomplishment. For example, a computer-based system to support video-conferencing will need to provide for the input and output of sound and of moving images at each point-of-use, whereas an application- 
program to compile and format printed documents will not normally require such facilities.

Although it is generally useful to distinguish between settings and scenes, it is nevertheless true that certain settings are regularly associated with particular scenes. Employing a term from Koile et al. (2003), we may describe such conjunctions as 'activity zones.' For example, computer laboratories serve activity zones for practical programming classes and such like.

\subsection{Broader situational context}

Let us now turn to the broader situational context, beginning with its physical aspect. The hierarchical structure of context is very much in evidence here, as can be seen when the broader situational context is described in terms of the following physically-based categories:

(15) a. The universe (or perhaps the multiverse, if there is more than one universe)

b. The world

c. Geographical areas of the world

The smallest element (15c) within this hierarchy is of a size which cannot be specified in advance, but which needs to be determined by the analyst. For example, if two people wish to communicate via a telecommunication network whose coverage extends over England, Wales and Scotland, then Great Britain constitutes the relevant area. On the other hand, if the network covers just one university campus, then it is this much smaller area that is pertinent to the aspect of the contextual analysis in question.

As for the socio-cultural side of the broader socio-cultural context, this encompasses the following:
a. Social structure
b. Cultural norms
c. Economics
d. History
e. Semiotic modes available

Society is internally differentiated, and may be described in terms of social groups and categories; cf. Goodman (1992: 42-71). In the case of a social group, for example an organization such as a university or a commercial company, members normally experience a common sense of identity and expected conduct. In some cases, this has a direct effect upon communication, for example the inclusion of a letterhead in written 
correspondence. On the other hand, social categories, for example the computer-literate, lack this perception of organic unity. It may be noted that social groups and categories are not necessarily confined to single countries. For example, the European Union (EU) is an international organization.

Prevailing cultural norms concern beliefs, values and ideologies. The laws of the relevant countries are included here, as are generally accepted conventions relating to politeness, respect and such like. An example of this type of consideration would be the norm whereby authors avoid reinforcing derogatory stereotypes of particular categories of people. Individual groups, such as commercial companies, may have their own internal cultures, too, involving particular ways of thinking and of regarding others.

Economic factors, especially cost, can be important contextual factors. For example, an expensive telecommunication link between different countries may serve to curtail conversations.

Historical factors, too, can be significant. For example, the growth of the Internet in the last twenty years has had a profound effect upon the ways in which people engage in communication and upon the range of texts available for them to consume.

The semiotic modes, such as languages and systems of non-verbal communication, which are available for use, manifestly exert a strong influence upon communication. An obvious example can be seen in the necessity for authors to choose a semiotic mode, such as a particular language, which will be understood by their audience.

\section{Cognitive context}

In HHI the context will be represented in some way in the minds of the participants in a discourse. After all, if the context is to influence what an author says or writes, then it must, indeed, be present mentally to him or her. Van Dijk (2006: 168-173) suggests that the internal representations in question comprise mental models in the sense of Johnson-Laird (1983).

In the light of these observations, we may distinguish (provisionally) between the following:
a. Mental context
b. External context

The 'external' context lies outside of the participants' minds, and consists of the phenomena covered in the previous sections of this paper under the headings of discoursal and situational context. The 'mental' context, on 
the other hand, comprises the representations of the context, both discoursal and situational, in the minds of the participants. In fact, certain aspects of context, notably the intended purpose of the discourse, are mental in origin and character, as well as constituting a factor in the social context of the discourse that may be perceived externally by the analyst.

The mental representations of the context of a discourse generally differ to some extent among the individuals involved. Nevertheless, when a discourse begins, there will almost inevitably be a certain amount of information that the participants all share, often termed the 'common ground'; cf. Clark and Carlson (1992 [1981]: 67-71), Stalnaker (1999: 97-102) and Givón (2005: 91-92). Typically, the purpose of the communicative activity is to increase the amount of common ground between author and audience; cf. Dik (1997: 8-12).

As the discourse proceeds, the participants maintain a recollection of what has been said so far. However, this may well not comprise a perfect recall of the actual co-text, but rather, it may constitute just a partial memory of the content of what has been said. Moreover, participants may infer implicit information that is not explicitly stated in a discourse. Thus, there is more to the mental representation of the discoursal context than a memory of the actual text; cf. Connolly (2001: 122).

As for the relationship between mental context and situational context, this again is far from straightforward. As already noted, the external context needs to be represented in the minds of the participants in some fashion. However, there may well be discrepancies between external reality and mental models thereof. Indeed, authors may hold beliefs that are objectively false, yet form part of the context if relevant to the discourse. Furthermore, it is not uncommon for people to talk about imaginary or hypothetical states-of-affairs, which exist only in the mind and have no counterpart in objective reality.

Mental representations are, of course, not amenable to direct observation, with the result that we may not be able to be precise about their nature or content. Nevertheless, we have no choice other than to acknowledge the importance of mental context in HHI.

Let us now turn from HHI to HCI. Here we encounter a somewhat different situation. To begin with, the internal representation of contextual information within computers takes the form of machine states, which are quite different from mental representations in humans and are amenable to direct observation by people with sufficient technical knowledge. Hence, the distinction drawn in (17) above is not adequate, as it stands, to cover both HCI and HHI. What we need to do is to replace (17) with the following distinction: 
(18) a. Cognitive context, which may be subdivided into:

i. Mental context

ii. Informatic context

b. External context

Whereas 'mental' context is represented within human minds, 'informatic' context comprises the representation of context within an electronic machine, such as a computer. The two may be grouped together under the general heading of 'cognitive' context (given the currency of the term 'cognitive science' to embrace the study of both natural and artificial intelligence). 'External' context retains essentially the same meaning as before, standing now in contrast to cognitive context. Note that the branching structure implicit in (18) reflects, yet again, the hierarchical organization of context.

Another difference between HHI and HCI is that in the latter case, the representation of context within the computer may be minimal. For example, if a user clicks on a button on the screen, then in order to respond, the computer needs to have an internal representation only of the fact that the user has clicked the button and of what to do in response (for example, to display another page of information). The contents of the human mind, in contrast, have the capacity to supply a far richer context, even for simple interactions.

On the other hand, in some cases the internal representation of relevant information within the system is extensive. For example, suppose that a user instructs the computer to retrieve the names of all the individuals on a company payroll stored in a large database, and that the computer responds by displaying these names on the screen. In that case, the voluminous contents of the database constitute an essential part of the informatic context of the human-computer dialogue.

Despite the differences between humans and computers, we have now, at least, managed to accommodate the different types of cognitive context within a single framework that provides for a compatible treatment of internally-represented context in both HHI and HCI. This brings to a close the exposition of our basic contextual framework.

\section{Comparison with other frameworks}

Various previous authors have also proposed frameworks aimed at the analysis and description of context. Some of these are very useful, and deserve our appreciation more than our criticism. Moreover, we acknowledge the influence that they have had on our own proposals. However, 
given that we have not adopted any of them as they stand, it behooves us to give a brief indication of the reasons behind our decision.

In the linguistics literature, two previous treatments of context may be regarded as classics. The first is the pioneering work of Firth (1957: 203), which focuses on the narrower context only. The second is the 'SPEAKING grid' put forward by Hymes (1972: 58-65). This has a much wider coverage, which includes the broader context. However, it does not articulate the hierarchical structure of context as well as it might. The same may also be said of the analysis proposed by Harris (1988: 78-81). Broadly-based frameworks are also offered by Cook (1992: 1-2) and by Goodwin and Duranti (1992: 6-9). Again, however, these frameworks again do not make the structure of context as explicit as might be wished.

On the other hand, the hierarchical nature of context is made very clear by Devlin (1991: 33, 217-221), whose account is based on Situation Theory, which, as Barwise (1989: 87-90) contends, constitutes an appropriate vehicle for the modelling of context. However, it is not really clear how multimodal discourse context should be dealt with in terms of Devlin's framework.

Eggins (2004: 9-11, 54-112), drawing partly on work by Halliday (1999), Martin (1992: 493-588, 1999) and others, also presents a wideranging coverage of context in which hierarchical structure is acknowledged. However, its emphasis is on the social rather than the physical aspect of context, whereas we are, in the present paper, equally concerned with both.

In the literature on computing, various attempts have been made to identify contextual factors, concentrating mainly on the immediate context. Examples include Schilit, Adams, and Want (1994), Abowd and Mynatt (2000), Dey, Abowd, and Salber (2001), Kirsh (2001) and Satyanarayanan (2001).

Two more recent contributions, in particular, are worthy of special mention. First, Te'eni, Carey, and Zhang (2006: 11-14, 302-303) offer a broadly-based, hierarchical framework for the purpose of supporting the development of interactive systems. However, they place the user and the task outside of the 'context,' in their application of the term. We, on the other hand, treat both user and task as part of the narrower situational context. Second, Bradley and Dunlop (2005) offer a good interdisciplinary survey of previous work on context and propose a wide-ranging, hierarchical framework to support work involving the development and evaluation of context-aware systems. However, although it offers a detailed treatment of the narrower context, their framework does not give as much weight as it might to the broader context. 


\section{Context and user-system dialogue}

In the remainder of this paper we propose to focus on the application of our own contextual framework to HCI. As noted above, communication between humans and computer-based systems is a process that is accomplished by means of a situated interactive discourse known as the usersystem dialogue (USD).

Our contextual framework may be employed in at least two ways in relation to HCI. First, it may be applied to the analysis and description of the USD with a view to enriching our understanding of the pragmatics of human-computer communication, much as previous contextual frameworks have been used by linguistic authors to help further our understanding of the semiotics of situated communicative interaction among humans. Second, it may benefit the developers of computer-based systems in producing requirements and designs in support of effective HCI. We shall now provide a brief example of both of these points.

\subsection{Illustrative contextual analysis}

First, suppose that we wish to persuade someone who is not already convinced that a considerable amount of contextual information is needed to support even a brief and simple USD. This would be an example of enriching the appreciation of a theoretical aspect of HCI. For example, consider the following USD:
a. U: While reading a page on university web-site, clicks on a link that consists of the text Fees for degree programmes

b. S: Displays a screen containing the text

Fees vary according to whether or not the student is a resident of the European Union (EU). Current fees for EU students:

$£ 4000$ per annum for full-time degree programmes.

$£ 2000$ per annum for part-time degree programmes.

Current fees for other students:

$£ 9000$ per annum for full-time degree programmes.

$£ 4500$ per annum for part-time degree programmes.

Beneath the text the screen contains a map of Europe, indicating the EU countries.

First of all, with regard to the external context the following factors may be regarded as relevant: 
(20) a. Narrower physical context

Participants:

The user and the system, within the USD.

The user and the author of the web pages, within the computer-mediated HHI facilitated by means of the HCI.

Time: the period described as 'current.'

Software: the browser programme that the user is utilizing.

Network connectivity: infrastructure supporting the use of the web.

b. Narrower social context

Roles:

The user, controlling the interaction.

The system, responding to the user's instruction.

Intended outcome:

For the user to discover information about fees for degree courses.

For the interaction to be successful in facilitating the accomplishment of this task.

Actual outcome: the achievement of the intended outcomes.

Occasion: an interaction between an individual and a computer-based system in an informal situation.

c. Narrower discoursal context

The appearance of the map alongside the text in order to make clear which countries belong to the EU.

d. Broader physical context

Geographical area: the continent of Europe.

e. Broader social context

International social structure: the political institution of the EU.

The economic concept of currency, and in particular the pound sterling (£).

The languages involved:

English: the principal language of the web-site.

Latin: the borrowed phrase 'per annum.'

f. Broader discoursal context

The web and its conventions, for example that underlined text generally represents a link.

With regard to the cognitive context, the user needs to possess an awareness and understanding of all of these contextual factors in order 
to participate meaningfully in the USD, to understand the information displayed by the system and to bring the USD through to successful completion. As the discourse proceeds, the user will derive information from it all the while, and the interpretation of each word, phrase and sentence will be influenced by what has gone before, so that the user's mental context will need to be continually updated for this purpose. The informatic context within the system includes the contents of the relevant web pages and the browser program, as well as the internal representation of program data, such as that which may result from the user clicking on links.

Our analysis thus shows not only that a good deal of contextual information is indeed needed in order to accomplish the USD in (19) successfully, but also which categories of contextual factors are involved and for what purpose. In this way it aids our explicit understanding of the factors that are essential to effective communication between humans and computer-based systems.

\subsection{Developer's perspective}

Second, suppose that a system developer who is aware of the importance of contextual factors in HCI wishes to ensure that these are taken into account when specifying the requirements for a system. The framework that we are proposing may be used as an aid in this endeavor. Even in those cases where the internal representation of context within the system is minimal, the developer's analysis of context needs to be sufficiently rich to ensure that the system is properly specified and designed.

Examples of contextual issues that need to be settled when specifying the requirements for an interactive system are the following, all of which relate to the external context:

(21) a. Narrower physical context

Who are the expected, ratified human participants?

What physical characteristics (including abilities and disabilities) will they have?

Is there a risk of unwanted, unratified participants?

With what computer hardware and software will the users interact?

Where and when will the system be used?

Will the physical environment be adverse, and if so, in what way? 
b. Narrower social context

What roles will be played by the participants in the interaction? For example, will users be interacting only with the system or will they also be communicating with other humans via the technological platform?

If there is a risk of unratified participants, do they create a requirement for techniques such as encryption to be deployed in order to exclude them?

What tasks will the interactive system be expected to accomplish?

What are the expected occasions of use? For example, will the system be employed in support of an individual making formal presentations to an audience, or will it be utilized in informal situations?

c. Narrower discoursal context

How will the structure of the USD be constrained?

d. Broader physical context

In what parts of the world will the system be used?

Will it be linked to the Internet?

e. Broader social context

Which human languages need to be supported?

Which laws and jurisdictions are applicable?

Which social groups, such as organizations, are involved?

What economic factors, such as costs, are relevant?

Are any historical factors relevant, for example the need for compatible with earlier, 'legacy' systems?

f. Broader discoursal context

What other documents (electronic or paper-based) will be available during the course of the interaction?

Examples of issues relating to the cognitive context are as follows:

(22) a. Mental context

What effects will the knowledge and experience of the users have upon the interaction?

What effects will the personal preferences and habits of the users have upon the interaction?

b. Informatic context

What information about the external context will need to be represented within the system? 
What software will need to be available within the system to support the interaction?

As will be apparent, then, our contextual framework offers a useful source of questions that can serve as prompts for the benefit of system developers. Although these are not the only questions that need to be posed, there is no doubt that they all deserve serious consideration.

\section{Two special cases}

There are two particular types of computer-based system that call for some further discussion in relation to the application of our contextual framework. We shall now deal with these in turn.

\subsection{Virtual and augmented reality}

The first type of system that we have in mind is that which goes under the name of 'virtual reality' (VR). The latter is described by Dix et al. (2004: 733 ) as 'the computer-generated simulation of a world, or a subset of it, in which the user is immersed.' In many cases the user has to wear special equipment such as goggles and data-gloves in order to experience and interact with the virtual world. The advantage, however, is that VR can enable the user to carry out activities which would be difficult or impossible in the real world, for example to fly around or through buildings.

Communicative interaction may be possible involving virtual beings situated within such simulated worlds. For example, the user may be able to engage in a dialogue with a virtual assistant inside a virtual store. Artificial representations of people, as in the example just given, are called 'avatars'; and it is possible that the user, too, may be represented an avatar; cf. Dix et al. (2004: 481).

In 'augmented reality' (AR), computer-generated images are projected onto the real world, resulting in a merging of the virtual and the actual. For example, video images may be projected onto a paper desktop; cf. Dix et al. (2004: 737).

What effect does the existence of VR and AR have upon our approach to context? First of all, it impels us to distinguish (when relevant) between 'actual' and 'virtual' aspects of the context of a USD in which VR or AR is involved. Having done so, it becomes possible to describe both the real and the virtual parts of the context in terms of the categories provided by our contextual framework. What then remains is to reconcile the two parts, by recognizing correspondences and/or distinctions between them. 
For example, suppose that a user is sitting at home, using an electronic shopping system that takes the form of a virtual bookstore. Within this virtual environment the user, represented by an avatar, interacts with a virtual salesperson, in order to purchase a dictionary, represented onscreen by the projection of a three-dimensional image. In relation to the virtual part of the context, it is clear that the setting (inside the bookstore) is distinct from the actual physical context in which the user is situated (at home). Nevertheless, either part of the context is open to description in terms of the same kinds of category, for example the location, the participants, and so on. With regard to the participants in the communicative activity, it may be noted that:

(23) a. In the virtual world the participants are the avatars.

b. In the actual world:

i. In the HCI the participants are the user and the system.

ii. In the computer-mediated HHI the participants are the user and the actual seller who owns the bookstore and is going to supply the actual book.

c. A direct correspondence exists between the human user and the user-avatar, and between the dictionary and its virtual representation.

This, then, provides a straightforward example of how the two aspects of the context may be reconciled through recognizing the distinctions and correspondences between them.

It is possible that corresponding elements in a virtual world and the actual world may be so close that it makes sense to describe the situation in terms of a contextual factor being shared, or 'distributed,' across both parts of the context. For example, the user's intention in purchasing the dictionary (above) is reflected in the behavior of the avatars, and it thus drives both the user's dialogue with the system and the user-avatar's dialogue with the salesperson-avatar. In this way, the purpose is distributed over the actual and virtual parts of the context.

To take another example, suppose that an AR system were to provide for the projection of xylophone keys onto a flat, plain surface that was able to sense impacts from lightweight hammers and, in response, to cause synthesized musical notes to be played from a loudspeaker attached to the system. The user, when wielding the hammers to play a tune, would be interacting simultaneously with the actual surface and with the virtual xylophone. The user's participation would therefore be distributed over both the actual and virtual parts of the system.

To sum up, it would seem that the existence of VR and AR systems call for a distinction to be drawn between actual and virtual aspects of the 
context, and for these to be reconciled with one another, but that otherwise, no further modification needs to be made to our contextual framework. We may therefore move on to consider the second of the special cases that we need to consider, namely context-aware (CA) systems.

\subsection{Context-aware systems}

As noted earlier, writings on CA systems tend to imply a view of context as relative to the systems themselves; see for example Brown, Bovey, and Chen (1997: 59-60), Antifakos and Schiele (2002: 313-315), Bauer, Becker, and Rothermel (2002: 324) and Beigl, Zimmer, and Decker (2002: 353). We are not suggesting that there is anything inherently wrong with such an approach, in circumstances where the interest does not lie in HCI. However, it would raise a major problem if we were to attempt to apply it to human communication with CA system. In such interaction, the participants would, of course, be the user and the system. Now, if the 'context' were understood as being supplied by the environment of the system (which is one of the participants in the interaction), then not only the other participant (the user) but also the dialogue itself would have to be regarded as part of the context.

Clearly, this would be inconsistent with the view that we have adopted in the present paper, namely that context is relative to the communication in which systems, including those of the CA variety, act as participants. In other words, we espouse the position that it is the discourse, rather than any interlocutor, that is to be treated as focal, while all discourseparticipants belong to the context.

To make such a claim is simple enough. However, human interactions with CA systems do not necessarily take the form of user-system dialogues in the familiar sense. For example, CA systems may be programmed to respond to the user's physical position in a room and to the direction in which he or she is facing. An example of such a system would be a handheld device of the type described by Oppermann and Specht (2000), which provided information to museum visitors in relation to the exhibit at which they were looking at a given time. The question that we need to answer, then, is: how do we identify the discourse in such an interaction?

The solution lies in one of the proposals put forward in Connolly, Chamberlain, and Phillips (2006: 215), namely that we should 'regard the user's position and orientation as kinds of non-verbal communication.' The user-to-system part of the USD then consists in manifesting such non-verbal signs, which are, in turn, detected and interpreted by the CA system. The system duly responds in the manner for which it has been 
programmed. (In the current example the response consists in presenting interesting information about a particular exhibit to the user.) In this way, we are able to maintain our discourse-focused approach to context in HCI, even in relation to CA systems.

Having adopted such a perspective, the application of our contextual framework offers no problem of general principle. However, the physical context may require a more finely-grained analysis than would be typical with other kinds of system. First of all, the location may be described in terms of categories such as the following:
a. Position
b. Orientation
c. Proximity
d. Layout

All of these are relevant to the current example: the layout of the exhibits in the room, the user's position in the exhibition space, the direction in which the user's face is oriented and the proximity of the user to an exhibit, given that the user needs to be close enough to manifest interest and hence to be offered information by the handheld guide. See also Brown, Bovey, and Chen (1997), José and Davies (1999) and Oppermann, Specht, and Jaciniak (1999).

For other CA applications, environmental factors may be relevant, including the following:
a. Temperature
b. Humidity
c. Lighting
d. Noise level
e. Weather conditions (if outdoors)

These are pertinent, for examples, in systems designed to regulate the environment in response to the presence of users, or to adjust output so as to maintain usability in adverse surroundings. See also Amor (2002: 30).

\section{Conclusion}

In conclusion, we believe that we have put forward in this paper a framework for the analysis and description of context that offers the following advantages. First, it is more broadly-based than any such framework previously available. Second, it explicitly articulates the hierarchical structure of context. Third, it readily accommodates the contextual analysis of multimodal dialogue. Fourth, it incorporates a notion of 'cognitive context' that encompasses both the mental context of humans and the 
informatic context supplied by the representation of information inside inanimate computer-based systems. Fifth, in presupposing throughout a focus on interactive discourse, it facilitates a consistent treatment of context both in HHI and in the different forms of HCI, including interaction involving recent technologies (VR, AR and CA) that have presented fresh challenges for contextual description. In sum, then, the framework supplies the systematic treatment of context that is needed in order to support our discourse-based approach to human-computer communication.

\section{References}

Abowd, G. D. and Mynatt, E. D. (2000). Charting past, present, and future research in ubiquitous computing. ACM Transactions on Computer-Human Interaction 17 (1), 2958.

Amor, D. (2002). Internet Future Strategies: How Pervasive Computing Services will Change the World. Upper Saddle River, NJ: Prentice-Hall.

Antifakos, S. and Schiele, B. (2002). Beyond position awareness. Personal and Ubiquitous Computing 6, 313-317.

Bauer, M., Becker, C., and Rothermel, L. (2002). Location models from the perspective of context-aware applications and mobile ad hoc networks. Personal and Ubiquitous Computing 6, 322-328.

Beigl, M., Zimmer, T. and Decker, C. (2002). A location model for communicating and processing of context. Personal and Ubiquitous Computing 6, 341-357.

Barwise, J. (1989). The Situation in Logic. Stanford, CA: CSLI.

Bradley, N. A. and Dunlop, M. D. (2005). Toward a multidisciplinary model of context to support context-aware computing. Human-Computer Interaction 20, 403-446.

Brown, P. J., Bovey, J. D., and Chen, X. (1997). Context-aware applications: From the laboratory to the marketplace. IEEE Personal Communications 4 (5), 58-64.

Bunt, H. (2000). Requirements for dialogue context modelling. In Formal Aspects of Context, P. Bonzon, M. Cavalcanti and R. Nossum (eds.), 23-36. Dordrecht: Kluwer.

Burkhardt, J. et al. (2002). Pervasive Computing: Technology and Architecture of Mobile Internet Applications. Boston, MA: Addison-Wesley.

Cicourel, A. V. (1992). The interpenetration of communicative contexts: Examples from medical encounters. In Rethinking Context: Language as an Interactive Phenomenon, A. Duranti and C. Goodwin (eds.), 291-310. Cambridge: Cambridge University Press.

Clark, H. H. and Carlson, T. B. (1992 [1981]). Context for comprehension. In Arenas of Language Use, H. H. Clark (ed.), 60-77. Chicago: University of Chicago Press.

Connolly, J. H. (2001). Context in the study of human languages and computer programming languages: A comparison. In Modelling and Using Context: Proceedings of the Third International and Interdisciplinary Conference CONTEXT 2001, Dundee, V. Akman et al. (eds.), 116-128. Berlin: Springer.

Connolly, J. H., Chamberlain, A., and Phillips, I. W. (2006). A discourse-based approach to human-computer communication. Semiotica 160 (1/4), 203-217.

Cook, G. (1990). Transcribing infinity: Problems of context presentation. Journal of Pragmatics 14, 1-24.

-(1992). The Discourse of Advertising. London: Routledge.

Devlin, K. (1991). Logic and Information. Cambridge: Cambridge University Press. 
Dey, A. K., Abowd, G. D., and Salber, D. (2001). A conceptual framework and a toolkit for supporting the rapid prototyping of context-aware applications. Human-Computer Interaction 16, 87-166.

Dik, S. C. (1997). The Theory of Functional Grammar, Part 1: The Structure of the Clause, K. Hengeveld (ed.). Berlin: Mouton de Gruyter.

Dix, A. et al. (2005). Human-Computer Interaction. Harlow: Pearson.

Dourish, P. (2004). What we talk about when we talk about context. Personal and Ubiquitous Computing 8, 19-30.

Eggins, S. (2004). An Introduction to Systemic Functional Linguistics, 2nd ed. New York: Continuum.

Firth, J. R. (1957). Papers in Linguistics 1934-1951. London: Oxford University Press.

Givón, T. (2005). Context as Other Minds: The Pragmatics of Sociality, Cognition and Communication. Amsterdam: Benjamins.

Goffman, E. (1981). Forms of Talk. Oxford: Blackwell.

Goodman, N. (1992). Introduction to Sociology. New York: Harper Collins.

Goodwin, C. and Duranti, A. (1992). Rethinking context: An introduction. In Rethinking Context: Language as an Interactive Phenomenon, A. Duranti and C. Goodwin (eds.), 142. Cambridge: Cambridge University Press.

Halliday, M. A. K. (1999). The notion of 'context' in language education. In Text and Context in Functional Linguistics, M. Ghadessy (ed.), 1-24. Amsterdam: Benjamins.

Harris, W. V. (1988). Interpretive Acts: In Search of Meaning. Oxford: Clarendon.

House, J. (2006). Text and context in translation. Journal of Pragmatics 38, 338-358.

Hymes, D. (1972). Models of the interaction of language and social life. In Directions in Sociolinguistics: The Ethnography of Communication, J. J. Gumperz and D. Hymes (eds.), 35-71. New York: Holt, Rinehart, and Winston.

Johnson-Laird, P. N. (1983). Mental Models. Cambridge: Cambridge University Press.

José, R. and Davies, N. (1999). Scalable and flexible location-based services for ubiquitous information access. In Handheld and Ubiquitous Computing: Proceedings of the First International Symposium, HUC 1999, Karlsruhe, H.-W. Gellersen (ed.), 52-66. Berlin: Springer.

Kirsh, D. (2001). The context of work. Human-Computer Interaction 16, 305-322.

Koile, K. et al. (2003). Activity zones for context-aware computing. In UbiComp 2003: Ubiquitous Computing: Proceedings of the Fifth International Conference, Seattle, A. Dey, A. Schmidt, and J. F. McCarthy (eds.), 90-106. Berlin: Springer.

Kress, G. and van Leeuwen, T. (1996). Reading Images: The Grammar of Visual Design. London: Routledge.

Martin, J. R. (1992). English Text: System and Structure. Amsterdam: Benjamins.

- (1999). Modelling context: A crooked path of progress in contextual linguistics. In Text and Context in Functional Linguistics, M. Ghadessy (ed.), 25-61. Amsterdam: Benjamins.

Martinec, R. (2000). Types of process in action. Semiotica 130 (3/4), 243-268.

Oppermann, R. and Specht, M. (2000). A context-sensitive nomadic exhibition guide. In Handheld and Ubiquitous Computing: Proceedings of the Second International Symposium, HUC 2000, Bristol, P. Thomas and H.-W. Gellersen (eds.), 127-142. Berlin: Springer.

Oppermann, R., Specht, M. and Jaceniak, I. (1999). Hippie: A nomadic information system. In Handheld and Ubiquitous Computing: Proceedings of the First International Symposium, HUC '99, Karlsruhe, H.-W. Gellersen (ed.), 330-333. Berlin: Springer.

Pemberton, L. (1996). Telltales and overhearers: Participant roles in electronic mail conversation. In Linguistic Concepts and Methods in CSCW, J. H. Connolly and L. Pemberton (eds.), 145-161. London: Springer. 
Satyanarayanan, M. (2001). Pervasive computing: Vision and challenges. IEEE Personal Communication 8 (4), 10-17.

Schilit, B., Adams, N. and Want, R. (1994). Context-aware computing applications. In Proceedings of the First IEEE Workshop on Mobile Computing Systems and Applications, Santa Cruz, 85-90. IEEE Press.

Stalnaker, R. C. (1999). On the representation of context. In Context and Content: Essays on Intentionality in Speech and Thought, R. C. Stalnaker (ed.), 96-113. Oxford: Oxford University Press.

Stamper, R. K. (2001). Organizational semiotics: Informatics without the computer? In Information, Organization, and Technology: Studies in Organizational Semiotics, K. Liu et al. (eds.), 115-171. Boston: Kluwer.

Te'eni, D., Carey, J. and Zhang, P. (2006). Human Computer Interaction: Developing Effective Organizational Information Systems. New York: Wiley.

Van Dijk, T. A. (2006). Discourse, context and cognition. Discourse Studies 8 (1), 159-177.

John Connolly (b. 1950) is a Senior Lecturer at Loughborough University <J.H.Connolly@ lboro.ac.uk $\rangle$. His research interests are semiotics, linguistics, computer-based communication, and context modelling. His publications include 'Accommodating natural language within the Organizational Semiotic framework' (2002); 'Semiotics and the theoretical foundations of Multimedia' (with I. W. Phillips, 2002); 'The question of discourse representation in Functional Discourse Grammar' (2004); and 'The pragmatics of programming languages' (with J. Cooke, 2004).

Alan Chamberlain (b. 1973) is a Research Fellow at University of Nottingham <azc@cs.nott .ac.uk $\rangle$. His research interests are mobile and wearable human-computer interaction, pervasive computing, accessible design, and critical interpretations of new technologies and new HCI-based frameworks. His publications include 'Designer, user, meaning maker: Rethinking relationships for a more creative HCI' (with D. England et al., 2004); 'Design considerations for elderly users in domestic pervasive environments' (with R. S. Kalawsky, 2004); and 'A comparative investigation into two pointing systems for use with wearable computers while mobile' (with R. S. Kalawsky, 2004).

Iain Phillips (b. 1967) is a Lecturer at Loughborough University〈I.W.Phillips@lboro.ac .uk $\rangle$. His research interests are internet performance, ad-hoc networking, and humancentered HCI. His publications include 'Semiotics and the theoretical foundations of multimedia' (with J. H. Connolly, 2002); 'Neural approach to detecting communication network events' (with J. M. Sandford and D. J. Parish, 2002); 'Using packet size distributions to identify real-time networked applications' (with D. J. Parish et al., 2003); and 'Presentation of real-time communication network measurement information' (with D. J. Parish et al., 2004). 